\title{
A DEFESA DA CONCORRÊNCIA NO SISTEMA FINANCEIRO: UM MODELO PARA O BRASIL'
}

\author{
Jean Paul Cabral Veiga da Rocha ${ }^{2}$ \\ Doutorando pelo Departamento de Direito Econômico e \\ Financeiro da Faculdade de Direito da Universidade de São Paulo
}

\begin{abstract}
Resumo:
Após resenhar as disputas dogmáticas sobre o conflito de competência entre o Conselho Administrativo de Defesa Econômica (CADE) e o Banco Central (Bacen), o presente trabalho apresenta a proposta de um novo desenho institucional para o controle de atos de concentração de instituições financeiras, sugerindo que a discussão contemporânea sobre a criação de uma Agência Nacional de Defesa do Consumidor e da Concorrência (ANC) pode e deve ser aproveitada para a implementação de um modelo que reduza a tensão entre regulação financeira e defesa da concorrência.
\end{abstract}

Abstract:

After a survey of the contradictory legal opinions concerning the tasks of the Brazilian competition agency (Conselho Administrativo de Defesa Econômica - CADE) and the Brazilian central bank (Banco Central - Bacen), this paper

1. Sou muito grato à FAPESP, cujo apoio financciro tem viabilizado a realização de projeto de pesquisa sobre regulação financeira c democracia, no âmbito do qual cstas breves notas foram redigidas. Devo agradecer tambćm a Otávio Yazbck, mcu colega da Pós-Graduação da Faculdade de Dircito da USP, pclos inestimávcis diálogos sobre a cstrutura institucional cos sistcmas financciros, $\mathrm{c}$ aos colcgas do Grupo de Pesquisa sobrc Reforma do Estado c Democracia, do Projeto Temático (FAPESP/CEBRAP) "Dircito c Democracia", Paulo Mattos, Mariana Prado c Vinícius Carvalho. Foi graças ao gentil convite c ao cstimulo do Prof. Ronaldo Porto Macedo Júnior que o nosso grupo de pesquisa, junto com cle, debruçou-se sobre o Anteprojeto de Lei que cria a Agência Nacional de Defesa do Consumidor c da Concorrência (ANC) c sobre o Anteprojeto de Lei que altera o Código de Defesa do Consumidor, Lei n. 8.078/90, c a Lei n. $8.884 / 94$, ambos sob consulta pública atć 31 de janciro último. As críticas e sugestõcs foram cnviadas $\mathrm{cm}$ nome do grupo para a Casa Civil da Presidência da República, c scrão publicadas na Revista de Dircito do Consumidor, no prclo. A última partc do presente trabalho reproduz a proposta de um dos itens do Rclatório do Grupo, o referentc ao controlc dos atos de concentração de instituiçõcs financciras. Entretanto, o presente trabalho foi cscrito $\mathrm{cm}$ carátcr pessoal, scndo o autor o único responsável pelas idéias aqui expostas.

2. Ex-bolsista do Programa de Formação de Quadros Profissionais do Ccntro Brasilciro de Análisc c Plancjamento (CEBRAP) c membro do gnupo de pesquisa "Rcforma do Estado c Democracia" do CEBRAP 
aims to propose a new institutional design for the control of mergers in financial services, by arguing that the Brazilian contemporary discussion about the reformulation of antitrust law should provide the opportunity for the implementation of a model that can reduce the tension between financial regulation and defense of competition.

Unitermos: Banco Central; CADE; concorrência; sistema financeiro; conflito de competência.

\section{Sumário:} entre CADE e Bacen;

1. Imbróglio dogmático e insegurança jurídica: o conflito de competência

2. As peculiaridades do mercado financeiro: regulação, inovação e concorrência;

3. Aproveitando a ANC: um modelo para o Brasil.

1. Imbróglio dogmático e insegurança jurídica: o conflito de competência entre CADE e Bacen

As estruturas institucionais do mercado financeiro têm sido desafiadas por três importantes tendências: a inovação financeira, o surgimento de conglomerados financeiros e a crescente dimensão internacional das operações financeiras. ${ }^{3}$ Nessa perspectiva, às questões básicas sobre o papel da(s) autoridade monetária(s), o número adequado de agências reguladoras, o grau possível e desejável de coordenação entre essas agências, a distribuição e conflito de competências entre estas, o papel do Ministério Público e do Poder Judiciário, a autonomia e accountability da autoridade monetária e das agências, vem se somar o problema da delimitação de competências entre os órgãos reguladores do mercado financeiro e o órgão de defesa da concorrência ${ }^{4}$

3. Cf. Charles Goodhart et al,'The institutional structurc of financial regulation", in GOODHART, Charles et al, Financial regulation: why, how and where now?, London/New York, Routledge, 1998, pp. 142-188.

4. Cf. Charles Goodhart et al, ob. cit., pp. 143-144. 
A questão, como é sabido, não é exclusividade do setor financeiro. $\mathrm{O}$ debate geral sobre regulação sempre suscita o tema da harmonização entre as atuações da autoridade antitruste e de cada agência reguladora setorial. $O$ tema mereceu a atenção da OCDE, por meio de sua Comissão de Política e Direito da Concorrência, produziu um interessante documento intitulado exatamente "Relação entre autoridades reguladoras e autoridades de defesa da concorrência". 5

Com base nos conceitos e esquemas classificatórios sugeridos pela OCDE, Oliveira e Pereira Neto, ${ }^{6}$ com o objetivo de analisar o setor de telecomunicações do Brasil, apontaram cinco possíveis configurações institucionais para a divisão de trabalho entre as autoridades de defesa da concorrência e de regulação. Elas variam de acordo com o modo como três funções básicas são distribuídas entre as autoridades: regulação técnica (RT- estabelecimento de normas, padrões e metas), regulação econômica (RE- estabelecimento de condições de preços, tarifas e quantidades), e aplicação da lei de defesa da concorrência (LC).

No primeiro modelo institucional possível (M1 isenção antitruste), todas as funções ficam com a agência reguladora. No segundo (M2 competências concorrentes), ambas as autoridades aplicam sanções antitruste e estabelecem regulação econômica. No terceiro (M3 - competências complementares), a autoridade de defesa da concorrência aplica a lei antitruste, enquanto a agência reguladora fica com as regulações econômica e técnica. No quarto modelo (M4 - regulação antitruste), todas as funções ficam com a autoridade de defesa da concorrência. No quinto (M5 desregulamentação), não há funções de regulação técnica nem econômica, mas tão somente a de aplicação da lei antitruste, que é exercida exclusivamente pela autoridade da concorrência. O quadro 1 infra sintetiza esta classificação.

Após argumentarem em defesa da superioridade do modelo das competências complementares, os autores investigam o aparente conflito de competência entre CADE e ANATEL, chegando então à conclusão de que é possível interpretar a Lei Geral de Telecomunicações (Lei n. 9.472/97) como instauradora de M3.

5. Organization For Economic Co-Operation and Development (OECD). Directorate for Financial, Fiscal and Enterprise Affairs. Committec on Competition Law and Policy (DAFFE/CLP), "Rclationship betwecn regulators and competition authorities", 29.06.99, www.oecd.org.

6. Gesner de Olivcira c Caio Mário da Silva Pcrcira Ncto, "Regulação c defesa da concorrência: bascs conccituais c modclo institucional do sctor de telccomunicaçõcs no Brasil”, mimeo, 1999. 


\begin{tabular}{|c|c|c|}
\hline Modelo/Autoridade & Autoridade Antitruste & Agência Reguladora \\
\hline M1 - Isenção antitruste & - & LC RE RT \\
\hline $\begin{array}{c}\text { M2 - Competências } \\
\text { concorrente }\end{array}$ & $\mathrm{s} R E+L C$ & $R E+L C+\mathrm{RT}$ \\
\hline $\begin{array}{c}\text { M3 - Competências } \\
\text { complementares }\end{array}$ & $\mathrm{LC}$ & $\mathrm{RE}+\mathrm{RT}$ \\
\hline $\mathrm{M} 4-$ Regulação antitruste & $\mathrm{LC}+\mathrm{RE}+\mathrm{RT}$ & - \\
\hline $\mathrm{M} 5-$ Desregulamentação & $\mathrm{LC}$ & - \\
\hline
\end{tabular}

Quadro 1: resumo dos modelos institucionais. Adaptado de Gesner de Oliveira e Caio Mário da Silva Pereira Neto. "Regulação e defesa da concorrência: bases conceituais e modelo institucional do setor de telecomunicações no Brasil” mimeo, 1999.

O esquema parece ser aplicável ao Banco Central, na medida em que ele, além de autoridade monetária, funciona também como agência reguladora do sistema financeiro ${ }^{7}$ Caberia, portanto, investigar, a partir da interpretação sistemática das Leis ns. 4.595/64 e 8.884/94, qual o modelo vigente para as relações CADE/Bacen.

Neste ponto o debate complica-se, na medida em que as disputas dogmáticas não chegaram a uma solução, especialmente quanto ao controle das estruturas $^{\mathrm{X}} \mathrm{O}$ noticiário econômico divulgou uma recente decisão do CADE que aprovou a compra da Patagon.com pelo Banco Santander," confirmando a tendência

7. Ao lado do Consclho Monetário Nacional, obviamente. Aliás, como ć sabido, na cstrutura dual da cúpula da regulação financcira $\mathrm{cm}$ nosso Pais, as funçõcs normativas cncontrain-sc nas mãos do CMN, cnquanto o Baccn atua muito mais como órgào que cxccuta a política monctária. Entretanto, por previsão cxpressa da Lci n. 4.595/64, ć ao Bacen que cabc autorizar as mudanças cstruturais das instituiçõcs financeiras (art. $\left.10^{\circ}, \mathrm{X}\right)$.

8. O controle das condutas, tanto na perspectiva da defesa da concorrência, quanto na do Dircito do Consumidor (âmbito de aplicação do Código de Defesa do Consumidor), também ć motivo de polêmica, mas não scrá abordado neste trabalho.

9. CADE busca atuar no mcrcado financciro. Gazeta Mercantil, São Paulo, 21 fcv. 200 I, Cadcrno Lcgal \& Jurisprudência, p. 1. 
apontada em decisões anteriores, ${ }^{10}$ no sentido de que o órgão assumiria definitivamente a competência para analisar e aprovar atos de concentração de instituições financeiras. A posição do CADE é polêmica e tem sido veementemente criticada pelo Bacen, que não aceita perder a competência privativa para tal controle.

De um lado, a favor do CADE, sustenta-se que o art. 54 da Lei n. 8.884/ 94 não cria exceções a sua competência geral para apreciar atos de concentração econômica. Não há nenhuma forma de isenção ou imunidade antitruste explícita, nem na lei, nem na Constituição. De outro lado, a favor do Bacen, são retomados cânones clássicos relativos ao conflito de normas no tempo para se chegar à conclusão de que a Lei n. 4.595/64 é lei específica referente ao sistema financeiro, incluindo a matéria da concorrência neste setor, o que afastaria a competência do CADE. Ainda a favor desta última conclusão, pesa o fato de ter sido a Lei n. 4.595 recepcionada como lei complementar, pois ainda não foi editada a Lei Regulamentadora do art. 192 da Constituição. A Lei n. 8.884, sendo lei ordinária, não poderia tratar de nenhum aspecto da matéria daquele artigo, qual seja, o sistema financeiro nacional. $\mathrm{O}$ argumento da superioridade hierárquica da Lei n. 4.595 enquanto lei complementar reforça todo o entendimento."

O espinhoso tema da relação entre lei complementar e lei ordinária já se tornou clássico no Direito Público brasileiro. Nem Pontes de Miranda escapou da confusão lógica que permeia a questão. Como observou José Afonso da Silva, Pontes de Miranda, ao comentar o art. 22 da Emenda Parlamentarista, numa mesma obra, ${ }^{12}$ depois de afirmar que as leis complementares eram leis ordinárias e que não eram leis constitucionais, ${ }^{13}$ afirmou, algumas páginas depois, que elas seriam de direito constitucional. ${ }^{14}$ Concluiu que as leis complementares não poderiam ser consideradas

10. Casos Daimler Chrysler/Consórcio Rodobenz c BNY/Banco Credibanco.

11. Ver BRASIL. Banco Central. Procuradoria-Geral, Parecer 2000/00762, de 18/10/2000, p. 9. A mesma linha de argumentação ć scguida por Arnoldo Wald, "O Banco Central, a Defesa da Livrc Concorrência c a Protcção do Consumidor nas Opcraçõcs Financciras", in Revista de Direito Bancário, do Mercado de Capitais e da Arbitragem, n. 10, p. 19.

12. Comentários à Constituição de 1946, t. VIII, Rio de Janciro, Borsoi, 1960.

13. Pontcs de Miranda, Comentários à Constituição de 1946, t. VIII, p. 180, apud José Afonso da Silva, Aplicabiliclade das Normas Constitucionais, 4a. cd., São Paulo, Malhciros, 2000. pp. 241-242.

14. Pontcs de Miranda, Comentários à Constituição de 1946, t. VIII, p. 184, apud José Afonso da Silva, Aplicabilidade das Normas Constitucionais, pp. 241-242. 
leis ordinárias puras, mas sim leis intercalares, situadas entre as emendas à Constituição e as leis ordinárias. ${ }^{15}$

O debate ganhou grande repercussão na doutrina brasileira do Direito Tributário. O aprofundamento dogmático do tema - que não é o objetivo do presente trabalho - passa necessariamente pela rediscussão da clássica monografia de José Souto Maior Borges. ${ }^{16}$ Crítico da tese da hierarquia, Souto Maior Borges, com seu inconfundível rigor lógico, sustentou ser a lei complementar resultante de um regime material e formal:

"Quando a lei complementar extravasa do seu âmbito material de validade, para disciplinar matéria de competência de legislação ordinária da União, é substancialmente lei ordinária. Como não é o rótulo, o nomen juris que caracterizará o fenômeno, nem tampouco o simples quorum de aprovação, a lei 'complementar será, em verdade, lei ordinária, podendo ser revogada - é claro - por outra lei ordinária editada pela União." $" 17$

A tese da inexistência de hierarquia entre lei complementar e lei ordinária foi defendida no voto do conselheiro Celso Campilongo, na análise do caso Santander/ Patagon.com, já referido. ${ }^{18}$ Em sua argumentação, o passo lógico seguinte para a afirmação da competência do CADE foi a recepção pela Constituição, de 1988, de parte da Lei n. 4.595/64 como lei complementar (trechos relativos à matéria do art. 192 da Constituição, qual seja, sistema financeiro nacional), e de outra parte, relativa à defesa da concorrência, como lei ordinária - pạrte esta já revogada pela Lei n. 8.884/94, lei ordinária. ${ }^{19}$

Este curioso fenômeno de recepção mista da Lei n. 4.595/64 (meia complementar, meia ordinária) já foi aceito pelo Supremo Tribunal Federal na ADIn n. 449-2-DF. ${ }^{20}$ A decisão unânime considerou que as normas da Lei n. 4.595/64 relativas

15. Pontes de Miranda, Comentários à Constituição de 1946, t. VIII, p. 180, apud Josć Afonso da Silva, Aplicabilidade das Normas Constitucionais, 4a. cd., São Paulo, Malheiros, 2000. pp. 241-242.

16. Lei Complementar Tributária, São Paulo, RT/Educ, 1975. Ver tambćm, do mesmo autor, "Lci complementar em Dircito Constitucional Intertemporal (ICMS)", in Revista Dialética de Direito Tributário n. 5 , fcv. 1996, pp. $50-57$

17. Lei Complementar Tributária, p. 27.

18. BRASIL. Conselho Administrativo de Defesa Econômica (CADE). Ato de Concentração $n^{\circ}$ 08012.007435/00-02. Voto de vista do Consclhciro Cclso Campilongo, 15/01/01, p. 2.

19. Idem, ibidem.

20. BRASIL. Supremo Tribunal Fedcral. Ação Dircta de Inconstitucionalidade n. 449-2 - Distrito Federal. Relator: Ministro Carlos Velloso. 29 de agosto de 1996. D.J. de 22/11/1996. 
ao pessoal do Banco Central foram recebidas pela Constituição, de 1988, como normas ordinárias. O leading case representa um duro golpe nos defensores da tese da hierarquia.

Apesar do pronunciamento do STF, ainda persiste, por parte da doutrina, a sustentação da superioridade hierárquica da lei complementar. Hugo de Brito Machado, em breve, porém sugestivo artigo, ${ }^{21}$ a partir do argumento de que é o elemento formal, e não o material, que determina a hierarquia entre as normas, sustenta que uma lei ordinária não pode revogar trechos de uma lei complementar que não tratam de matéria reservada, pela Constituição, à lei complementar. Defender o contrário, sustenta o autor, é promover a insegurança jurídica, uma vez que o campo das matérias atribuídas pela Constituição à lei complementar é impreciso.

É esta idéia de imprecisão do rol de matérias atribuídas que permite ao Banco Central, mediante sua Procuradoria Geral, alegar que o art. 192 da Constituição não traz um rol taxativo - o caput diz "inclusive" - da matéria que deve ser tratada por lei complementar. Como defesa da concorrência no mercado financeiro é matéria lógica e funcionalmente indissociável da regulação financeira, lei ordinária não poderia dela tratar. ${ }^{22}$

A posição de Hugo de Brito Machado é considerada nominalista por José Afonso da Silva. Segundo este autor, a banalização do conceito de lei complementar levaria, no limite, a uma situação absurda em que poderia haver exclusivamente leis complementares. A interpretação sistemática da Constituição elaborada por José Afonso da Silva leva à confirmação da tese de Souto Maior Borges. ${ }^{23}$ Os dois terminam por defender, na verdade, uma posição intermediária, aceitando a relação hierárquica nos casos em que a lei complementar fundamenta a validade de outros atos normativos, mas não reconhecendo aquela relação, quando a lei complementar trata de uma situação concreta. ${ }^{24}$

Um posicionamento absolutamente contrário à existência de hierarquia é sustentado por Celso Bastos, ${ }^{25}$ respaldado por decisão do Supremo Tribunal Federal

21. "Posiçào hicrárquica da lci complementar", in Revista Dialética de Direito Tributário, n. 14, nov. 1996, p. 19-22.

22. BRASIL. Banco Central. Procuradoria-Gcral, Parecer 2000/00762, de 18/10/2000, pp. 9-10.

23. Aplicabilidade das Normas Constitucionais, pp. 249-250.

24. Aplicabilidade das Normas Constitucionais, p. 247.

25. "A incxistência de hicrarquia entrc a lei complementar c as leis ordinárias", in Cadernos de Direito Tributário e Finanças Públicas, n. 26, pp. 11-20. No mesmo sentido argumentam Michel Temer c Roquc Antonio Carrazza, citados pclo autor. 
que afirma situar-se a lei complementar "no plano da legislação ordinária, não assumindo hierarquia constitucional" ${ }^{26}$ A parte mais interessante da argumentação de Bastos consiste em ressaltar que o critério da hierarquia para a solução do conflito de normas só deveria ser utilizado, quando existe um campo material comum. ${ }^{27}$ É o que ocorre na relação entre lei e regulamento, em que os campos materiais deste último são demarcados pela lei. ${ }^{28}$ Celso Bastos vai além, e sustenta ser vedado à lei complementar invadir o campo de atuação da lei ordinária. ${ }^{29}$ A tese por ele defendida, acatada por parte da doutrina brasileira, é totalmente oposta àquela sustentada por Hugo de Brito Machado.

Como se vê, em termos estritamente jurídico-formais, a confusão é tão grande que chega a se refletir em alguns trabalhos doutrinários contemporâneos, como o de Jairo Saddi, ${ }^{30}$ cuja ambigüidade leva o leitor a ter a impressão de que três interpretações distintas são defendidas ao mesmo tempo: (1) a competência deve ser exercida pelo CADE: ${ }^{31}$ (2) ela pertence ao Bacen, pois este é especializado, e o CADE já estaria assoberbado com "suas próprias atividades";32 (3) as competências deveriam ser repartidas de acordo com a matéria, ficando o Bacen com o controle das estruturas de impacto na atividade monetária, e o CADE com aquelas relevantes para o mercado de consumo (p. ex.: cartões de crédito). ${ }^{33}$

Um caminho mais sofisticado busca na doutrina jurídica norte-americana do pervasive power a solução para o problema. ${ }^{34}$ Sua conclusão sugere que o Bacen não possui a competência tão discutida, pois nunca a exerceu, não havendo, portanto,

26. Agravo regimental cm Agravo de instrumento, Processo 90741, j. 22.03.1983. Votação unânimc, resultado improvido. Rclator Min. Nćri da Silvcira. Apud Cclso Bastos, ob. cit., p. 14.

27. Celso Bastos, ob. cit., p. 16.

28. Cclso Bastos, ob. cit., p. 18.

29. Cclso Bastos, ob. cit., p. 19.

30. "Concentração no sistcma financciro nacional", in Revista de Direito Econômico, n. 26, ag-dcz.l 1997, pp. 29-36. A ambigüidade não desaparcce cm outro texto do autor, "Aprovação pclo Banco Central dc controlc de instituição financcira", in: Revista de Dircito Bancário c do Mcrcado de Capitais, n. 5, pp. 86-99.

31. "Concentração no sistema financciro nacional", p. 34.

32. "Concentração no sistema financciro nacional", p. 36.

33. "Concentração no sistema financciro nacional", p. 34.

34. Calixto Salomão Filho Análise juridica do poder econômico nos mercados: uma perspectiva estrutural, Tese de Livre Docência, Faculdade de Dircito da USP, 1996, pp. 152-160. Do mesmo autor, ver também "Condutas anticoncorrenciais no sctor bancário", in RDM 114, pp. 51-62, c Regulação da 
imunidade antitruste para os atos de concentração de instituições financeiras. Essa tese esbarra, porém, na objeção à importação automática da jurisprudência da Suprema Corte norte-americana para o nosso sistema jurídico.

Um recente parecer da Advocacia Geral da União aparentemente encerrou a discussão. ${ }^{35}$ Abraçando a argumentação da Procuradoria Geral do Bacen, o consultor da República Luiz Alberto da Silva foi taxativo:

"[...] à luz da legislação vigente, a competência para analisar e aprovar os atos de concentração das instituições integrantes do sistema financeiro nacional, bem como de regular as condições de concorrência entre instituições financeiras, aplicando-lhes as penalidades cabiveis, é privativa, ou seja, exclusiva do Banco Central do Brasil, com exclusão de qualquer outra autoridade, inclusive o CADE" ${ }^{36}$

Logo em seguida, não deixou de mandar o seu "recado" aos críticos da tese pró-Bacen:

"Esse é o modelo que foi adotado pela legislação vigente. Caso se entenda que esse não éo melhor modelo, a adoção de outro dependerá de modificação dos dispositivos da Lei n. 4.595/64 aqui analisados, o que somente poderá ser feito mediante lei complementar" 37

O que mais impressiona no Parecer é a inabalável conviç̧ão de seu autor. Parágrafos antes da conclusão ele já não titubeava:

"Reduzida a controvérsia a suas devidas proporções, como definido no anterior item 48 [o objeto especifico da consulta, que é a competência para analisar e aprovar os atos de concentração das instituições integrantes do Sistema Financeiro

\footnotetext{
Atividade Econômica-principios e fundamentos juridicos, São Paulo, Malhciros, 2001, pp. 46-50 e 133. Esta última obra, recentemente cditada, consistc num original csforço de criação de uma tcoria jurídica gcral da regulação cconômica c da concorrência, a partir de uma perspectiva institucional, no âmbito da qual a doutrina do pervasive power ć retomada para compatibilizar os objetivos regulatórios de higidez c scgurança sctorial com a concorrência. Como já ressaltado, não ć objetivo do presente trabalho aprofundar a análise doutrinária deste $\mathrm{c}$ dos demais autores citados, mas simplesmente registrar a quercla, para demonstrar, com sua amplitude c diversidade, a necessidade de mudar a legislação o mais rápido possivel, com vistas à climinação da inscgurança jurídica.
}

35. Parccer AGU/LA-01/2001, de 07 de feverciro de 200I, claborado pelo Consultor da União Luiz Albcrto da Silva, adotado pclo Advogado-Gcral da União, Gilmar Ferreira Mendes (Parccer GM-020, de 05 de abril de 2001).

36. Parccer AGU/LA-01/200l, itcm V, \$96.

37. Parecer AGU/LA-01/200I, item V, \$97. 
Nacional], parece evidente que correto é o entendimento da Procuradoria-Geral do Banco Central'"38 (grifei).

O que parece ser um dos mais complexos e delicados problemas envolvendo conflito de competência no direito brasileiro encontrou, nas sóbrias linhas do Consultor, uma solução "evidente" Seu parecer foi adotado pela Advocacia Geral da União e aprovado pelo presidente da República. Dessa forma, passou a vincular a Administração Federal, nos termos da Lei Orgânica da Advocacia Geral da União. ${ }^{39}$

A intervenção da AGU, órgão que deve prestar "consultoria e assessoramento jurídicos ao presidente da República" ${ }^{40}$ suscita uma outra polêmica. Se o presidente, mediante a aprovação de parecer da AGU, pode restringir a competência do CADE e das agências reguladoras, a autonomia destes órgãos é posta em xeque. Afinal de contas, o Advogado Geral da União, "o mais elevado órgão de assessoramento jurídico do Poder Executivo", é "submetido à direta, pessoal e imediata supervisão do presidente da República" 41 Não é este o lugar para desenvolver este tema, mas, à primeira vista, esta competência da AGU e da Presidência é um mecanismo de diminuição dos poderes daqueles órgãos. Dentre as atribuições do Advogado Geral da União, encontram-se as seguintes: (a) fixar, em caráter vinculante, a interpretação da Constituição e das leis para os órgãos e entidades da Administração Federal; ${ }^{42}$ (b) unificar a jurisprudência administrativa, garantir a correta aplicação das leis, prevenir e dirimir as controvérsias entre os órgãos jurídicos da Administração Federal.$^{43}$ É difícil vislumbrar a compatibilidade dessas competências com a autonomia do CADE e da defesa da concorrência. Nada impede que o tema seja levado ao Judiciário pelos interessados. Talvez, então, num

38. Parccer AGU/LA-01/200I, item IV, §50.

39. Lci complementar n. 73/93: "art. 40. Os pareccres do Advogado Gcral da União são por cstc submetidos à aprovação do Presidente da República. $\S 1^{\circ} \mathrm{O}$ parccer aprovado $\mathrm{c}$ publicado juntamentc com o despacho presidencial vincula a Administração Federal, cujos órgãos c cntidades ficam obrigados a lhe dar ficl cumprimento. $\S 2^{\circ} \mathrm{O}$ pareccr aprovado, mas não publicado, obriga apenas as repartiçõcs interessadas, a partir do momento cm que dele tenham ciência."

40. LC 73/93, art. $1^{\circ}, \S$ único.

41. LC 73/93, art. $3^{\circ}, \S 1^{\circ}$.

42. LC 73/93, art. $4^{\circ}, X$.

43. LC $73 / 93$, art. $4^{\circ}, \mathrm{XI}$. 
órgão não vinculado ao Executivo, as complexas questões aqui sumariamente apontadas sejam, todas elas, levadas em consideração.

De qualquer forma, é dificil imaginar qual seria o posicionamento do Judiciário. A enorme perplexidade criada por tamanho desencontro de opiniões tem uma causa mais profunda. Ao contrário do que sugere uma visão formalista do tema, boa parte da ambigüidade jurídica e dos conflitos de competência entre a autoridade antitruste e o Banco Central não deriva somente de leis mal formuladas, mas também de tensões inerentes à regulação financeira.

2. As peculiaridades do mercado financeiro: regulação, inovação e concorrência

As tensões existentes entre regulação financeira e defesa da concorrência são claramente expostas por Cristina Penido de Freitas ${ }^{44}$. A autora, pesquisadora da Fundap, escreveu uma tese de doutoramento sobre o tema da concorrência bancária numa perspectiva alternativa à do mainstream. Neste ponto, ele revela sua filiação a uma certa corrente teórica, alternativa à neoclássica, que tem se dedicado ao tema da concorrência no Brasil, representada principalmente por Mario Luiz Possas. Suas principais influências são Marx, Schumpeter e Keynes. Rejeita a visão convencional, estática, que vê a concorrência como estrutura de mercado em oposição ao monopólio. Em relação à noção neoclássica de concorrência perfeita contrapõe a visão da concorrência como um processo dinâmico. Passo, neste ponto, a um resumo da exposição de Cristina Freitas.

Na concepção que adota, a concorrência é o resultado da auto-expansão do capital, a busca da diferenciação como forma de obter vantagens, ainda que temporárias, de natureza monopolista. Muda-se, assim, radicalmente, o enfoque: não é a igualdade dos concorrentes, mas sim a sua diferenciação que passa a ser o principal mecanismo estratégico das empresas na concorrência capitalista. As famosas falhas de mercado passam a ser encaradas como características essenciais, e não patológicas, do próprio processo competitivo.

No caso do sistema bancário, este processo de diferenciação via inovação financeira é mais intenso, pois não existem patentes para produtos financeiros. Dessa forma, o ciclo inovação - imitação - inovação é mais rápido do que nos outros setores da economia. Do ponto de vista microeconômico, a inovação surge da busca de vantagens de caráter monopolista. Do ponto de vista macroeconômico, a inovação

44. "A naturcza particular da concorrência bancária c scus cfcitos sobrc a cstabilidadc financcira", in Economia e Sociedade, n. 8, jun. 1997, pp. 51-83. 
propicia o aumento do nível de endividamento da economia, ajustando a oferta de financiamento à demanda.

Este processo gera, entretanto, duas graves conseqüências: diminui a capacidade do Banco Central de influenciar a criação de moeda e aumenta o risco sistêmico, já que o refinanciamento de dívidas passadas cria estruturas patrimoniais instáveis ao longo do ciclo econômico. A posição privilegiada que os bancos ocupam no sistema econômico - criadores de moeda e intermediários financeiros - faz com que haja uma tensão intrínseca entre os objetivos de concorrência e de estabilidade do sistema financeiro. Quanto mais concorrência, mais ocorre inovação, mais se burla a regulação prudencial, e maior é a tendência à concessão excessiva de crédito e à especulação financeira.

A análise de Cristina Freitas sobre a concorrência no mercado financeiro, aqui rapidamente resumida, parece autorizar a conclusão de que, se a autoridade monetária tende a ver a manipulação do nível de concorrência como instrumento para calibrar a segurança do sistema bancário e do sistema de pagamentos, e se, por seu turno, a autoridade antitruste tende a ver na concorrência um valor superior, o desafio de um modelo institucional para a relação Banco Central/autoridade antitruste é diminuir ao máximo esta tensão, já que é impossível eliminá-la. Neste sentido, percebe-se como as discussões jurídicas dogmáticas, vez por outra travadas no Brasil, pecam por sua abordagem estritamente formal de tensões que estão no âmago do próprio sistema capitalista.

A situação atípica do recente processo de reestruturação bancária no Brasil levou o então presidente do CADE, Gesner de Oliveira, a defender (em nome pessoal, e não do órgão) uma isenção antitruste ad hoc:

"A nossa lei fala em motivos preponderantes da economia nacional. $O$ que ocorreu em termos de reestruturação do setor bancário desde 1988, 1989 até agora, é uma situação absolutamente atípica. Parece-me que essa reestruturação e essas operações que ocorreram mereceriam uma isenção antitruste. Quer dizer; mereceriam ser aprovadas sem o exame convencional, mas de maneira clara pelas autoridades, de forma a dar segurança, para que daqui a cinco anos ninguém venha dizer que esta lei não foi cumprida, que o Cade teria de analisar e não fez isso. Repito, teria de ser uma coisa muito clara. O que aconteceu, dadas as competências, dada a situação: aprovamos as operações, ou em bloco ou de outra forma. Enfim, teríamos de ver a melhor forma juridica para se fazer isso. Seria ö que passou, passou" 45

45. Gesner de Olivcira, "A cvolução do sistema bancário c a necessidade de harmonização da atuação dos organismos reguladores", palcstra reproduzida in ASBACE/CADE/MJ, Seminário Internacional sobre Regulação e Defesa da Concorrência no Setor Bancário, Brasília, s/d, p. 31. 
Portanto, no caso brasileiro, além das tensões inerentes ao processo concorrencial capitalista geral, ainda há o complicador da reestruturação bancária, principalmente em sua fase posterior à implantação do Planno Real.

\section{Aproveitando a ANC: um modelo para o Brasil}

Diante de tamanha confusão, o Anteprojeto de Lei que cria a ANC deveria aproveitar a oportunidade de resolver, com clareza, o atual conflito de competência entre o órgão responsável pela regulação prudencial (Banco Central) e o órgão antitruste (CADE), no que se refere ao exame de atos de concentração (Lei n. 4.595/64, art. $10^{\circ}$ $\mathrm{X}$, versus Lei n. 8.884/94, art. 54). Como já discutido, a existência de interpretações jurídicas díspares, a falta de entendimento formal e informal entre Bacen e CADE, e a falta de uma decisão judicia ${ }^{46}$ sobre aquele conflito de normas levam a uma insuportável insegurança jurídica.

Na prática, a atuação do CADE no exame de atos de concentração de instituições financeiras tem sido mínima. Mesmo após o parecer da Advocacia Geral da União, não está clara, nem para o mercado, nem para os operadores do direito, a delimitação de competências. Portanto, o desenho institucional do controle de atos de concentração neste setor deve levar em conta as seguintes questões: (a) a reestruturação bancária dos últimos anos fez com que a preocupação com a estabilidade sistêmica prevalecesse sobre a preocupação com a concorrência; (b) esse processo de reestruturação, extremamente delicado, desenrolou-se sob o comando do Governo Federal e do Banco Central (não-autônomo), por envolver o interesse público (estabilidade do sistema bancário e do sistema de pagamentos), caracterizando-se, portanto, como situação excepcional; (c) atualmente em fase mais avançada, a reestruturação já comporta uma atuação mais incisiva do órgão antitruste autônomo, mais preocupado com o valor da concorrência do que com os aspectos prudenciais; (d) a este factível cenário de transição deve corresponder um arranjo institucional maleável, que concilie as exigências da regulação prudencial, da defesa da concorrência e do consumidor e da defesa do interesse nacional; (e) não podem pairar dúvidas sobre a legalidade das fusões e aquisições já consumadas, mas que não foram submetidas ao CADE.

Diante do exposto, propõe-se que sejam acrescentados ao texto do Anteprojeto e da proposta de alteração da Lei n. 8.884/94 dispositivos que estabeleçam 
a seguinte sistemática de exame prévio de atos de concentração de instituições financeiras:

(1) o ato de concentração deverá primeiramente ser submetido ao órgão de regulação prudencial (seja ele o Banco Central ou qualquer outro que venha a substituí-lo no exercício dessa função específica, nos termos da lei que regulamentará o art. 192 da Constituição Federal), que o examinará estritamente quanto aos aspectos prudenciais;

(2) se o órgão de regulação prudencial não aprovar a operação, o exame prévio será encerrado com esta decisão denegatória, que será soberana;

(3) entretanto, se o ato for aprovado, ele deverá obrigatoriamente ser submetido à ANC, nos termos de sua lei específica;

(4) se a ANC aprovar o ato, com ou sem restrições, o exame prévio é encerrado, e a decisão da ANC é soberana;

(5) se a ANC não aprovar o ato, as instituições financeiras envolvidas poderão, no prazo de 15 dias, interpor recurso perante o ministro da Fazenda;

(6) após o recebimento dos autos, o ministro terá o prazo de 30 dias para decidir pela confirmação ou pela reforma da decisão;

(7) se decidir pela aprovação, o ministro deverá obrigatoriamente determinar restrições de caráter estrutural que diminuam o impacto negativo sobre a concorrência;

(8) concomitantemente, em defesa do interesse público, o ministro poderá condicionar a aprovação do ato à aceitação, pelas instituições financeiras envolvidas, de cláusulas de preservação de empregos e direitos dos trabalhadores, de abertura ou manutenção de agências bancárias em determinadas regiões etc.;

(9) o desrespeito a qualquer um dos dois prazos referidos implicará a confirmação tácita da decisão da ANC;

(10) a decisão do ministro é discricionária, não cabendo, portanto, recurso, nem ao presidente da República nem ao Poder Judiciário, a não ser que tenham ocorrido vícios formais, como, por exemplo, desrespeito aos prazos legais, ou se o ministro for omisso quanto à determinação de restrições de caráter estrutural (item 7, supra);

(11) para preservação da segurança jurídica, disposições transitórias deverão expressamente declarar a eficácia jurídica de todos os atos de concentração que, sob o regime jurídico anterior, foram aprovados pelo Banco Central, mas consumaram-se sem se submeterem ao CADE. 
Como se percebe, este esboço de proposta criaria um regime especial para os atos de concentração envolvendo instituições financeiras. É melhor que o regime atual, cercado de indefinições, e que vem sendo controlado, na prática, pelo Banco Central. Além disso, segue as diretrizes da OCDE, que defende a submissão desses atos ao órgão antitruste. É um modelo, por assim dizer, de equilíbrio, que realoca poderes entre o órgão regulador prudencial, a autoridade antitruste e de defesa do consumidor, e o Governo Federal, propiciando um balanceamento entre os valores da defesa da concorrência e do consumidor, da estabilidade do sistema financeiro, do interesse público e do interesse nacional.

Esse tipo de arranjo institucional, que permite, em nome daquele balanceamento, uma intervenção decisiva do ministro da área econômica, é adotado, com variações, na Austrália, no Canadá, na Alemanha, na Suíça e no Reino Unido. ${ }^{47}$

São Paulo, junho de 2001.

47. Ver o Relatório da OCDE, intitulado Mergers in Financial Services, de setembro de 2000, claborado pelo scu Committee on Competition Law and Policy, disponivel no sitc www.oecd.org. Sobre o Canadá, vcr tambćm a publicação Seminário Internacional sobre Regulação e Defesa da Concorrência no Setor Bancário, quc traz conferências e debates do cvento com o mesmo nome realizado $\mathrm{cm}$ março de $1999, \mathrm{~cm}$ Brasilia, pclo CADE c pela ASBACE - Associação Brasileira de Bancos Estaduais e Regionais 
Bibliografia

BASTOS, Celso. "A inexistência de hierarquia entre a lei complementar e as leis ordinárias". In: Cádernos de Direito Tributário e Finanças Públicas, n. 26, pp. 1120.

BRASIL. Advocacia-Geral da União. Parecer AGU/LA-01/2001, 07/02/2001.

BRASIL. Banco Central. Procuradoria-Geral. Parecer 2000/00762, 18/10/2000.

BRASIL. Conselho Administrativo de Defesa Econômica (CADE). Ato de Concentração n. 08012.007435/00-02. Voto de vista do conselheiro Celso Campilongo, 15/01/01.

BRASIL. Supremo Tribunal Federal. Ação Direta de Inconstitucionalidade $\mathrm{n}$. 449-2 - Distrito Federal. Relator: ministro Carlos Velloso. 29/08/1996. D.J. de 22/11/ 1996.

CADE busca atuar no mercado financeiro. Gazeta Mercantil, São Paulo, 21 fev. 2001, Caderno "Legal \& Jurisprudência" p. 1.

COUTINHO, Paulo. "Regulação prudencial e concorrência no setor bancário" In: ASBACE/CADE/MJ, Seminário Internacional sobre Regulação e Defesa da Concorrência no Setor Bancário, Brasília, s/d, pp. 205-232.

FREITAS, Cristina Penido de. "A natureza particular da concorrência bancária e seus efeitos sobre a estabilidade financeira" In: Economia e Sociedade, n. 8, jun. 1997, pp. 51-83.

HORTA, Rafael Alves. "A concentração bancária no Brasil" In: ASBACE/ CADE/MJ, Seminário Internacional sobre Regulação e Defesa da Concorrência no Setor Bancário, Brasília, s/d, pp. 233-254.

MACHADO, Hugo de Brito. "Posição hierárquica da lei complementar" In: Revista Dialética de Direito Tributário, n. 14, nov. 1996, pp. 19-22.

OLIVEIRA, Gesner; PEREIRA NETO, Caio Mário da Silva. "Regulação e defesa da concorrência: bases conceituais e modelo institucional do setor de telecomunicações no Brasil" mimeo, 1999.

OLIVEIRA, Gesner. "A evolução do sistema bancário e a necessidade de harmonização da atuação dos organismos reguladores" palestra reproduzida in: ASBACE/CADE/MJ, Seminário Internacional sobre Regulação e Defesa da Concorrência no Setor Bancário, Brasília, s/d, pp. 20-32.

ORGANIZATION FOR ECONOMIC COOPERATION AND DEVELOPMENT (OECD). Directorate for Financial, Fiscal and Enterprise Affairs. 
Committee on Competition Law and Policy (DAFFE/CLP). "Relationship between regulators and competition authorities", 29.06.99, www.oecd.org

"Enhancing the role of competition in the regulation of banks"

11.09.1998, www.oecd.org.

"Mergers in financial services", 20.09.2000, www.oecd.org.

SADDI, Jairo. "Concentração no sistema financeiro nacional" In: Revista de Direito Econômico, n. 26, ag.-dez./1997, pp. 29-36.

"Aprovação pelo Banco Central de controle de instituição financeira" In: Revista de Direito Bancário e do Mercado de Capitais, n. 5, pp. 86-99.

SALOMÃO FILHO, Calixto. Análise jurídica do poder econômico nos mercados: uma perspectiva estrutural, tese de livre docência, Faculdade de Direito da USP, 1996.

"Condutas anticoncorrenciais no setor bancário" In: RDM 114, pp. 51-62.

- Regulação da Atividade Econômica-principios e fundamentos juridicos, São Paulo, Malheiros, 2001.

SILVA, José Afonso da. Aplicabilidade das Normas Constitucionais, 4". ed., São Paulo, Malheiros, 2000.

SOUTO MAIOR BORGES, José. Lei Complementar Tributária, São Paulo, RT/Educ, 1975.

"Lei complementar em Direito Constitucional Intertemporal (ICMS)" In: Revista Dialética de Direito Tributário n. 5, fev. 1996, pp. 50-57.

SOUZA, Marcos Martins de. "Organização das instituições financeiras e o CADE” In: Revista de Direito Econômico, n. 24, jul.-dez./1996, pp. 73-77.

WALD, Arnoldo. "O Banco Central, a Defesa da Livre Concorrência e a Proteção do Consumidor nas Operações Financeiras" In: Revista de Direito Bancário, do Mercado de Capitais e da Arbitragem, n. 10, p. 19. 